\title{
Analisis Pengendalian Mutu Jambu Kristal dengan Metode Six Sigma di ADC IPB-ICDF Taiwan Bogor
}

\author{
Raisha Pratidina \\ Departemen Manajemen, Fakultas Ekonomi dan Manajemen \\ Institut Pertanian Bogor \\ Kampus IPB Darmaga 16680 \\ Muhammad Syamsun \\ Departemen Manajemen, Fakultas Ekonomi dan Manajemen \\ Institut Pertanian Bogor \\ Kampus IPB Darmaga 16680 \\ Nur Hadi Wijaya \\ Departemen Manajemen, Fakultas Ekonomi dan Manajemen \\ Institut Pertanian Bogor \\ Kampus IPB Darmaga 16680 \\ e-mail: nur.hadi.wijaya@gmail.com
}

\begin{abstract}
Quality Management is one of success keys of a company to become a market leader and reach its goal. This is also the case with Agribussiness Development Center (ADC) Bogor Agricultural University (IPB)-Taiwan International Cooperative Development Fund (ADC IPB-ICDF Taiwan). The most popular product of this company is Crystal Guava which has hardly any-seeds, sweet taste and crunchy meat. In 2012, this company have could only fulfill 31\% of Crystal Guava market demand for grade A and 69\% for grade B+, B and C. Analysis method used in this study is Defect per Opportunity (DPO) Analysis, Defect per million Opportunity (DPMO) Analysis, Process Flow Diagram, Pareto Chart, Control Chart, Fishbone Diagram, Failure Mode and Effect Analysis and Six Sigma Method. Based on analysis results, there are six Critical to Quality (CTQ); namely, seeding, environmental conditions, fertilizing, maintenance, harvest and post harvest. Furthemore, the calculation of sigma range shows that, sigma capability during 2012, on production Crystal Guava in ADC IPB-ICDF Taiwan, Bogor was still in 2-sigma. This reveals that there are many defects of Crystal Guava and its sigma capability is still below the target of capability (3.4 sigma). In the words, this moment, ADC IPB-ICDF Taiwan is not realistic in applying six sigma method on quality control of Crystal Guava due to viable agricultural yields and is affected by a number of factors, especially environmental factors that is difficult to control.

Keywords : crystal guava, quality control, six sigma
\end{abstract}

\begin{abstract}
ABSTRAK
Manajemen mutu merupakan salah satu kunci sukses perusahaan untuk memenangkan pasar dan mencapai tujuannya. Begitu juga yang harus dilakukan oleh Agribussiness Development Center (ADC) Institut Pertanian Bogor (IPB)-Taiwan International Cooperative Development Fund (ADC IPB-ICDF Taiwan). Produk unggulan dari perusahaan adalah jambu Kristal yaitu buah dengan biji yang sedikit, rasa manis dan renyah. Tahun 2012, perusahaan hanya mampu memenuhi sebesar 31\% permintaan pasar atas jambu Kristal grade A, serta grade B+, B dan C mencapai 69\%. Metode analisis yang digunakan adalah Analisis Defect per Opportunity (DPO), Analisis Defect per million Opportunity (DPMO), Diagram Alir Proses (Process Flow Diagram), Diagram Pareto (Pareto Chart), Peta Kendali, Diagram Sebab Akibat
\end{abstract}


(Fishbone Diagram), Failure Mode and Effect Analysis (FMEA) dan Metode Six Sigma. Berdasarkan hasil analisis, terdapat enam Critical To Quality (CTQ) antara lain pembibitan, kondisi lingkungan, pemupukan, perawatan, panen dan pasca panen. Hasil perhitungan kapabilitas sigma selama tahun 2012 masih berada kisaran 2-sigma. Hal ini menunjukkan masih banyak defect dan kapabilitas sigma berada di bawah target (3.4 DPMO). Dengan demikian, untuk saat ini ADC IPB-ICDF Taiwan Bogor masih belum realistis untuk mengaplikasikan six sigma dikarenakan produk agribisnis yang rentan dan dipengaruhi oleh berbagai faktor alam yang sulit untuk dikendalikan.

Kata kunci : jambu Kristal, pengendalian mutu, six sigma

\section{Pendahuluan}

Menurut Montgomery (2009), pengendalian dan peningkatan mutu menjadi strategi bisnis yang penting bagi banyak organisasi di tengah persaingan. Pengontrolan dan peningkatan mutu diartikan mengurangi variabilitas yang terjadi dalam proses dan produk akhir yang sering menyebabkan pemborosan biaya dan waktu. Oleh karena itu, perusahaan harus mengembangkan efektivitas pelaksanaan manajemen mutu di setiap tahapan proses produksinya.

Agribussiness Development Center (ADC) merupakan kerjasama di bidang pertanian antara Taiwan International Cooperative Development Fund (ICDF Taiwan) dengan Institut Pertanian Bogor (IPB) yang bertujuan meningkatkan taraf hidup petani. Berbagai macam produk pertanian dihasilkan antara lain sayuran organik, non organik dan buah. Buah yang menjadi unggulan adalah jambu Kristal, yaitu buah dengan rasa manis, renyah, ukuran relatif besar dan memiliki biji yang sedikit.

Potensi peluang bisnis jambu Kristal masih sangat besar, hal ini dikarenakan permintaannya yang tinggi sedangkan pasokannya masih rendah. Kekurangan pasokan dibandingkan permintaan supermarket yang ada di Bogor dan Jakarta terhadap jambu Kristal grade A di ADC IPB-ICDF Taiwan Bogor yang signifikan dapat dilihat pada Tabel 1.

Tabel 1. Perbandingan antara permintaan supermarket dan pasokan jambu Kristal

\begin{tabular}{lccc}
\hline \multicolumn{1}{c}{ Bulan } & Permintaan $(\mathbf{K g})$ & Pasokan $(\mathbf{K g})$ & Kekurangan $(\mathbf{K g})$ \\
\hline Oktober 2011 & 5820 & 3679.8 & 2140.2 \\
November 2011 & 3848 & 1608 & 2240 \\
Desember 2011 & 3848 & 2562.9 & 1285.1 \\
Januari 2012 & 3613 & 2816.7 & 796.3 \\
Februari 2012 & 4280 & 4190 & 90 \\
Maret 2012 & 2491 & 1852 & 639 \\
April 2012 & 2491 & 2175.8 & 315.2 \\
Mei 2012 & 1930 & 395.9 & 1534.1 \\
Juni 2012 & 2076.5 & 720.6 & 1355.9 \\
Juli 2012 & 3779.8 & 2126.5 & 1653.3 \\
Agustus 2012 & 1829 & 404,6 & 1424.4 \\
September 2012 & 1846 & 525 & 1321 \\
\hline TOTAL & $\mathbf{3 7 8 5 2 . 3}$ & $\mathbf{2 3 0 5 7 . 8}$ & $\mathbf{1 4 7 9 4 . 5}$ \\
\hline
\end{tabular}

Sumber : ADC IPB-ICDF Taiwan, Bogor (2012)

Data pada Tabel 1 menunjukkan bahwa dalam jangka waktu 12 bulan perusahaan tidak dapat memenuhi permintaan jambu Kristal grade A dari supermarket sebesar $14794.5 \mathrm{Kg}$. Dalam hal ini, perusahaan telah kehilangan kesempatan untuk meningkatkan penjualannya sebesar Rp295 890000 (jumlah kekurangan permintaan 
dikalikan dengan harga jambu Kristal grade A/Kg, yaitu Rp20 000). Masalah tersebut dipicu karena persentase produk cacat yang dihasilkan yaitu produk jambu Kristal dengan grade $\mathrm{B}+$, B dan C adalah 69\% dari total jumlah panen selama tahun 2012 sebagaimana terlihat pada Gambar 1.

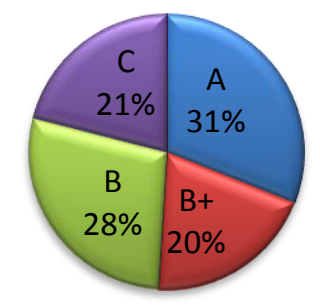

Gambar 1. Perbandingan persentase jumlah produk jambu Kristal per grade (ADC IPB ICDF Taiwan, Bogor 2012)

Penelitian ini dilakukan untuk meningkatkan pengendalian mutu jambu Kristal di ADC IPB-ICDF Taiwan Bogor melalui tindakan pencegahan terhadap penyebab potensial dari produk cacat, sehingga mutu yang dihasilkan lebih baik dan pendapatan meningkat (Deming dalam Nasution 2005). Analisis pengendalian mutu ini dilakukan dengan metode six sigma yang merupakan salah satu studi yang cukup revolusioner yang dikembangkan oleh Motorola untuk menerapkan jumlah defect (Sartin 2009). Metode six sigma dilakukan melalui perbaikan pada hal-hal berikut, antara lain pengurangan biaya, perbaikan produktivitas, pertumbuhan pangsa pasar, pengurangan waktu siklus, retensi pelanggan, pengurangan cacat, juga melalui perubahan budaya kerja dan pengembangan produk atau jasa (Miranda 2006). Metode ini juga digunakan untuk perhitungan pergeseran sigma pada proses produksi produk pertanian seperti jambu Kristal. Hal ini dilakukan untuk mengetahui tingkat cacat jambu Kristal di ADC IPB-ICDF Taiwan Bogor dan memberikan gambaran baseline kinerja awal perusahaan untuk melakukan pengendalian mutu pada proses produksi jambu Kristal kedepannya.

Tujuan dari penelitian ini : 1) Mengetahui pengelolaan produksi jambu Kristal di ADC IPB-ICDF Taiwan Bogor dalam usaha menghasilkan jambu Kristal yang bermutu; 2) Menganalisis pengendalian mutu pada pengelolaan produksi jambu Kristal; 3) Mengidentifikasi sebab-sebab potensial yang memengaruhi mutu produk jambu Kristal di ADC IPB-ICDF Taiwan Bogor, dan 4) Mengetahui kisaran sigma pengendalian mutu jambu Kristal di ADC IPB-ICDF Taiwan Bogor saat ini.

\section{Metode Penelitian}

Penelitian ini menggunakan data primer dan sekunder. Data primer diperoleh dari pengamatan langsung di lapangan, pengisian kuisioner dan hasil wawancara dengan tim jambu Kristal yang terdiri dari Counterpart IPB, pihak ICDF Taiwan, pekerja di packing room dan juga petani yang terlibat langsung dalam kegiatan produksi. Sedangkan data sekunder diperoleh dari informasi dan pencatatan historis perusahaan. Data penunjang juga diperoleh dari internet dan literatur di perpustakaan. Kerangka pemikiran penelitian dapat dilihat pada Gambar 2. 


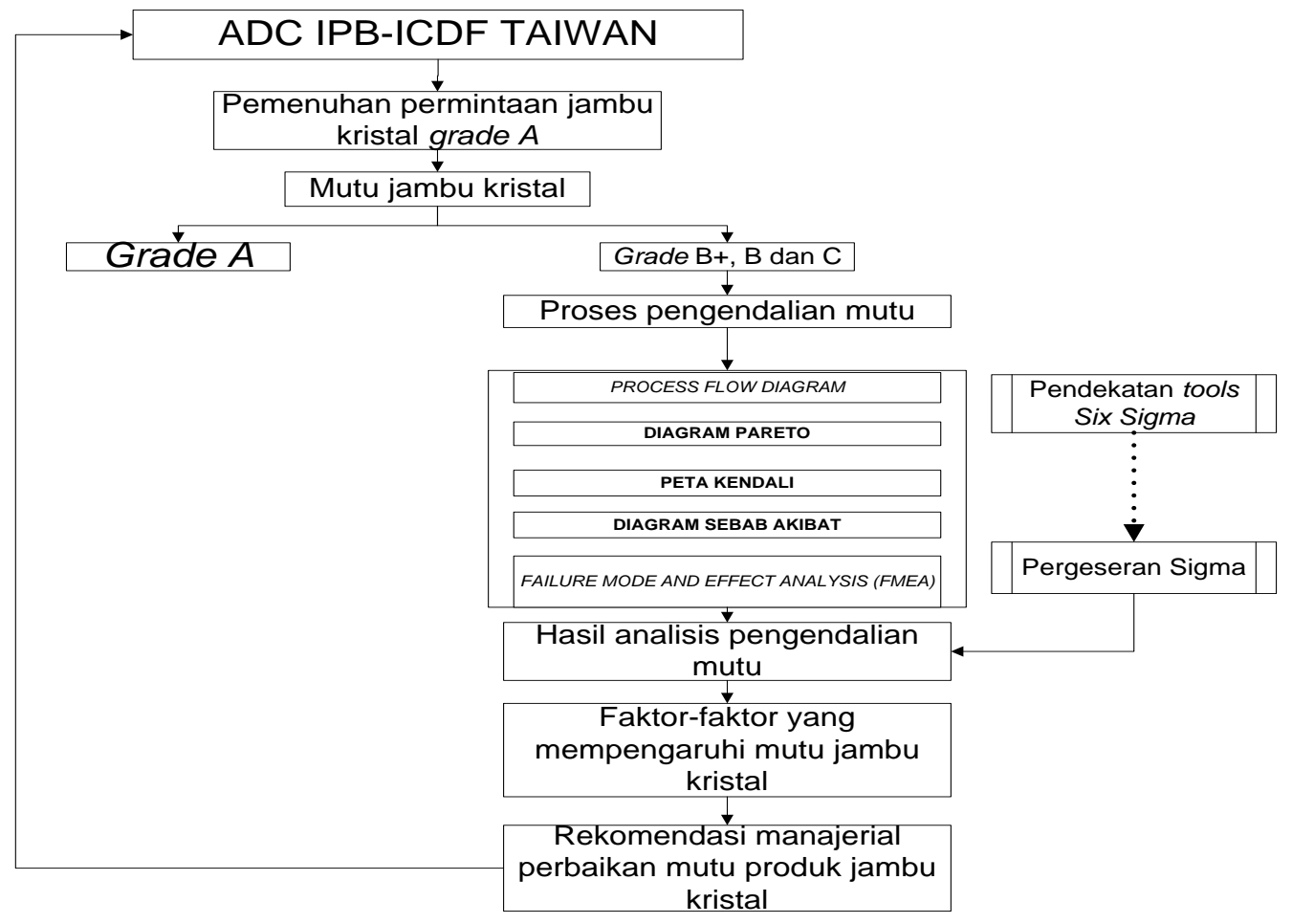

Gambar 2. Kerangka pemikiran penelitian

Tahapan penelitian ini mengacu pada Gaspersz dalam Dewi (2012) untuk menyelesaikan masalah dan peningkatan proses melalui tahapan Define, Measure, Analyze, Improve, Control (DMAIC) dengan menggunakan lima alat kendali mutu sebagaimana terlihat pada Tabel 2, yaitu :

1. Analisis Defect per Opportunity (DPO)

DPO merupakan salah satu analisis yang digunakan untuk mengukur proporsi cacat atas jumlah total peluang dalam sebuah kelompok.

$$
\mathrm{DPO}=\frac{\text { Jumlah defect }}{\text { Jumlah panen } \mathrm{x} \text { jumlah CTQ }}
$$

2. Analisis Defect per million Opportunity (DPMO)

DPMO mengindikasikan berapa banyak defect yang akan muncul dalam satu juta peluang.

$$
\mathrm{DPMO}=\mathrm{DPO} \times 1.000 .000
$$

3. Diagram alir proses (Process Flow Diagram)

Diagram alir proses (flowchart) merupakan alat yang menunjukkan masukan, keluaran dan tindakan dari suatu sistem (Gaspersz 2007).

4. Diagram pareto (Pareto Chart)

Pareto chart digunakan untuk memperbandingkan berbagai kategori kejadian yang disusun menurut ukurannya, dari yang paling besar di sebelah kiri ke yang paling kecil di sebelah kanan (Gaspersz 2007). 
Tabel 2. Lima fase siklus perbaikan DMAIC

\begin{tabular}{|c|c|c|}
\hline & Perbaikan Proses & Desain/Desain Ulang Proses \\
\hline 1. Define & $\begin{array}{l}\text { 1. Identifikasi masalah } \\
\text { 2. Definisi kebutuhan } \\
\text { 3. Menetapkan tujuan }\end{array}$ & $\begin{array}{l}\text { 1. Identifikasi masalah tertentu } \\
\text { 2. Definisi tujuan/perubahan visi } \\
\text { 3. Memperjelas jangkauan dan kebutuhan } \\
\text { pelanggan }\end{array}$ \\
\hline 2. Measure & $\begin{array}{l}\text { 1. Mempertegas masalah/proses } \\
\text { 2. Membenarkan pengetahuan } \\
\text { tujuan } \\
\text { 3. Mengukur langkah-langkah inti/ } \\
\text { masukan }\end{array}$ & $\begin{array}{l}\text { 1. Mengukur kinerja kebutuhan } \\
\text { 2. Mengumpulkan data secukupnya }\end{array}$ \\
\hline 3. Analyze & $\begin{array}{l}\text { 1. Mengembangkan hipotesis } \\
\text { 2. Identifikasi akar penyebab utama } \\
\text { 3. Validasi hipotesis }\end{array}$ & $\begin{array}{l}\text { 1. Identifikasi praktis terbaik } \\
\text { 2. Nama desain proses } \\
\text { - Pertambahan nilai atau tidak } \\
\text { - Bottleneck/disconnect } \\
\text { - Alternatif lainnya } \\
\text { 3. Memperjelas kebutuhan }\end{array}$ \\
\hline 4. Improve & $\begin{array}{l}\text { 1. Mengembangkan ide untuk } \\
\text { menghilangkan akar penyebab } \\
\text { permasalahan } \\
\text { 2. Uji solusi } \\
\text { 3. Menetapkan solusi/ hasil } \\
\text { pengukuran }\end{array}$ & $\begin{array}{l}\text { 1. Mendesain proses baru } \\
\text { - Asumsi-asumsi yang } \\
\text { mendukung } \\
\text { - Kreativitas } \\
\text { - Kebijakan proses kerja } \\
\text { 2. Menjalankan proses, struktur dan sistem } \\
\text { baru }\end{array}$ \\
\hline 5. Control & $\begin{array}{l}\text { 1. Membuat standar pengukuran } \\
\text { 2. Menyelesaikan permasalahan } \\
\text { sesuai dengan tujuan yang } \\
\text { diinginkan }\end{array}$ & $\begin{array}{l}\text { 1. Membuat pengukuran dan kaji ulang } \\
\text { untuk memelihara kinerja } \\
\text { 2. Menyelesaikan permasalahan menurut } \\
\text { tujuan yang diinginkan }\end{array}$ \\
\hline
\end{tabular}

Sumber : Gaspersz dalam Dewi (2012)

5. Peta kendali

Teknik mutu yang umum dilakukan ialah dengan menggunakan peta kendali. Diagram ini digunakan untuk mengendalikan jumlah barang yang rusak per unit secara keseluruhan hasil dalam suatu proses produksi (Feigeumbaum dalam Nasution 2005).

6. Diagram Sebab Akibat (Fishbone Diagram).

Suatu pendekatan terstruktur yang memungkinkan dilakukan suatu analisis lebih terperinci dalam menemukan penyebab-penyebab suatu masalah, ketidaksesuaian, dan kesenjangan yang terjadi (Gaspersz 2007).

7. Failure Mode and Effect Analysis (FMEA)

Analisis sistematis mode kegagalan potensial yang bertujuan untuk mencegah kegagalan (Ramadhani et al. 2009).

\section{Hasil dan Pembahasan}

III.1. Gambaran Umum Perusahaan

Misi Teknik Taiwan bekerjasama dengan University Farm IPB bergerak di bidang usaha proyek agribisnis yang kemudian diberi nama Agribusiness Development Center (ADC). Alamat kantor ADC IPB-ICDF Taiwan Bogor berada di Cikarawang RT/RW 003/007, Kecamatan Darmaga, Kabupaten Bogor, Jawa Barat. Proyek agribisnis di 
Bogor mendapatkan kesepakatan antara IPB dan Taiwan Technical Mission (TTM) untuk didirikan pada bulan April 2006. Kemudian persiapan lahan dilakukan pada bulan Mei 2006. Lahan ADC IPB-ICDF Taiwan Bogor kurang lebih seluas enam Hektar yang terdiri dari pos satpam, garasi, tempat parkir, kantor, tempat pembibitan, tempat pembimbingan, packing room, green house, lahan demonstrasi dan lahan produktif. Kegiatan utama yang dilakukan antara lain penyuluhan dan demonstrasi, pelatihan, workshop dan kunjungan, produksi bibit, bantuan pemasaran dan pameran promosi. Struktur organisasi di ADC IPB-ICDF Taiwan Bogor terdiri dari anggota Misi Teknik Taiwan yang mengelola proyek agribisnis di Bogor. Sedangkan, pihak University Farm IPB mengirimkan counterpart untuk pengelolaan dan pembinaan di setiap produk agribisnis yang dihasilkan.

Tiga sub proyek yang dilakukan oleh ADC IPB-ICDF Taiwan Bogor adalah pemasaran produk agribisnis sayuran organik, sayuran non organik dan jambu Kristal. Kegiatan produksi dilakukan dimulai dari pengolahan, penyortiran, pengemasan, penyimpanan dan pengiriman. Produk agribisnis yang dijual oleh ADC IPB-ICDF Taiwan Bogor berasal dari lahan yang ditanam dan dirawat sendiri, serta dari petani mitra. Sistem kerjasama dengan petani mitra, yaitu sistem yarnen (bayar saat panen), yakni sistem yang pada awalnya petani diberikan bibit, kemudian saat panen hasil panen tersebut dipotong untuk pembayaran bibit. Sistem yarnen di ADC IPB-ICDF Taiwan Bogor diberlakukan potongan $25 \%$ untuk pelunasan bibit tiap pengiriman jambu. Bentuk kemitraan yang dibangun antara petani dengan TTM, yaitu petani berperan sebagai produsen utama dari komoditi-komoditi yang dikembangkan dan TTM berperan sebagai tenaga pendamping bagi petani untuk mendapatkan produksi yang lebih baik. Petani mitra untuk jambu Kristal berada di Desa Cikarawang, Desa Bantarsari dan Kabupaten Bogor yang hampir mencapai 126 orang. Jambu Kristal grade A dari petani mitra akan dibeli oleh ADC IPB-ICDF Taiwan Bogor dengan harga Rp15 000 per kg, sedangkan untuk grade B akan dibeli dengan harga Rp7 000 per kg dan untuk grade $\mathrm{C}$ akan dibeli dengan harga Rp5 000 per kg. Sedangkan harga jual untuk jambu Kristal grade A adalah Rp20 000/kg dan untuk jambu Kristal grade B+, B dan C adalah Rp11 000/kg.

\section{III.2. Pengelolaan Produksi Jambu Kristal}

Diagram Alir Proses menggambarkan tahapan pengelolaan produksi jambu Kristal mulai dari metode okulasi untuk pembuatan bibit tanaman hingga pendistribusian ke konsumen (Gambar 3). Sedangkan standar mutu jambu Kristal yang diterapkan di ADC IPB-ICDF Taiwan Bogor pada saat penyortiran dijelaskan pada Tabel

3. Tahapan pengelolaan produksi jambu Kristal, antara lain :

1. Panen

Jambu Kristal berbuah sepanjang tahun. Panen dilakukan dengan melakukan penjadwalan panen per line atau per petak.

2. Pembersihan buah

Buah yang dipanen dari lahan biasanya dilakukan pembersihan spons dan plastik, serta pencucian kulit buah di packing room. Sedangkan buah dari petani biasanya telah dibersihkan sendiri oleh masing-masing petani. 


\section{Penyortiran}

Setelah dilakukan pembersihan, jambu Kristal hasil panen akan disortir per grade mutunya yang dilakukan oleh penanggung jawab packing room bagian jambu Kristal.

Tabel 3. Standar mutu jambu Kristal per grade mutu

\begin{tabular}{|c|c|c|}
\hline No. & $\begin{array}{l}\text { Klasifikasi } \\
\text { Grade }\end{array}$ & Keterangan \\
\hline 1 & Grade A & $\begin{array}{l}\text { a. Ukuran buah seragam dan memiliki bobot lebih kurang } 300 \mathrm{~g} \\
\text { b. Bentuk buah mendekati bulat atau bulat sempurna } \\
\text { c. Warna kulit buah hijau muda } \\
\text { d. Tekstur permukaan buah mulus, tidak ada bercak kecokelatan akibat } \\
\text { serangan penyakit, kebusukan, atau akibat benturan fisik }\end{array}$ \\
\hline 2 & Grade B & $\begin{array}{l}\text { a. Ukuran buah } 250-300 \mathrm{~g} \\
\text { b. Bentuk buah tidak bulat sempurna } \\
\text { c. Tekstur permukaan terdapat sedikit bercak kecokelatan }\end{array}$ \\
\hline 3 & Grade C & $\begin{array}{l}\text { a. Ukuran buah tidak seragam, cenderung kecil sekitar } 250 \mathrm{~g} \\
\text { b. Tekstur permukaan buah tidak mulus, terdapat bercak kecokelatan dan } \\
\text { terdapat cacat akibat benturan fisik } \\
\text { c. Warna kulit buah kekuningan (terlalu matang) } \\
\text { d. Bentuk buah tidak sempurna }\end{array}$ \\
\hline
\end{tabular}

Sumber : ADC IPB-ICDF Taiwan Bogor (2012)

\section{Pengemasan}

Pada tahap ini buah yang telah disortir akan dipisahkan. Untuk grade A, akan dilakukan pengemasan yaitu dengan pemberian spons, plastik dan pemberian merek ADC IPB-ICDF Taiwan Bogor untuk dijual ke supermarket/toko buah. Sedangkan grade B dan C akan disimpan di dalam chiller untuk dijual kepada konsumen yang membeli di tempat.

5. Penyimpanan di chiller

Sebelum dikirim ke pembeli keesokan harinya, jambu Kristal grade A dikemas dan dimasukkan ke dalam kardus yang siap dikirim, serta disimpan terlebih dahulu ke dalam chiller untuk menjaga kesegaran dan mutu buah.

6. Pengiriman

Pengiriman buah jambu Kristal dilakukan setiap hari yaitu hari Senin sampai Minggu sesuai dengan project order (PO) yang diterima. Pengiriman jambu Kristal produksi ADC IPB-ICDF Taiwan Bogor antara lain ke supermarket dan toko buah di Bogor dan Jakarta. 


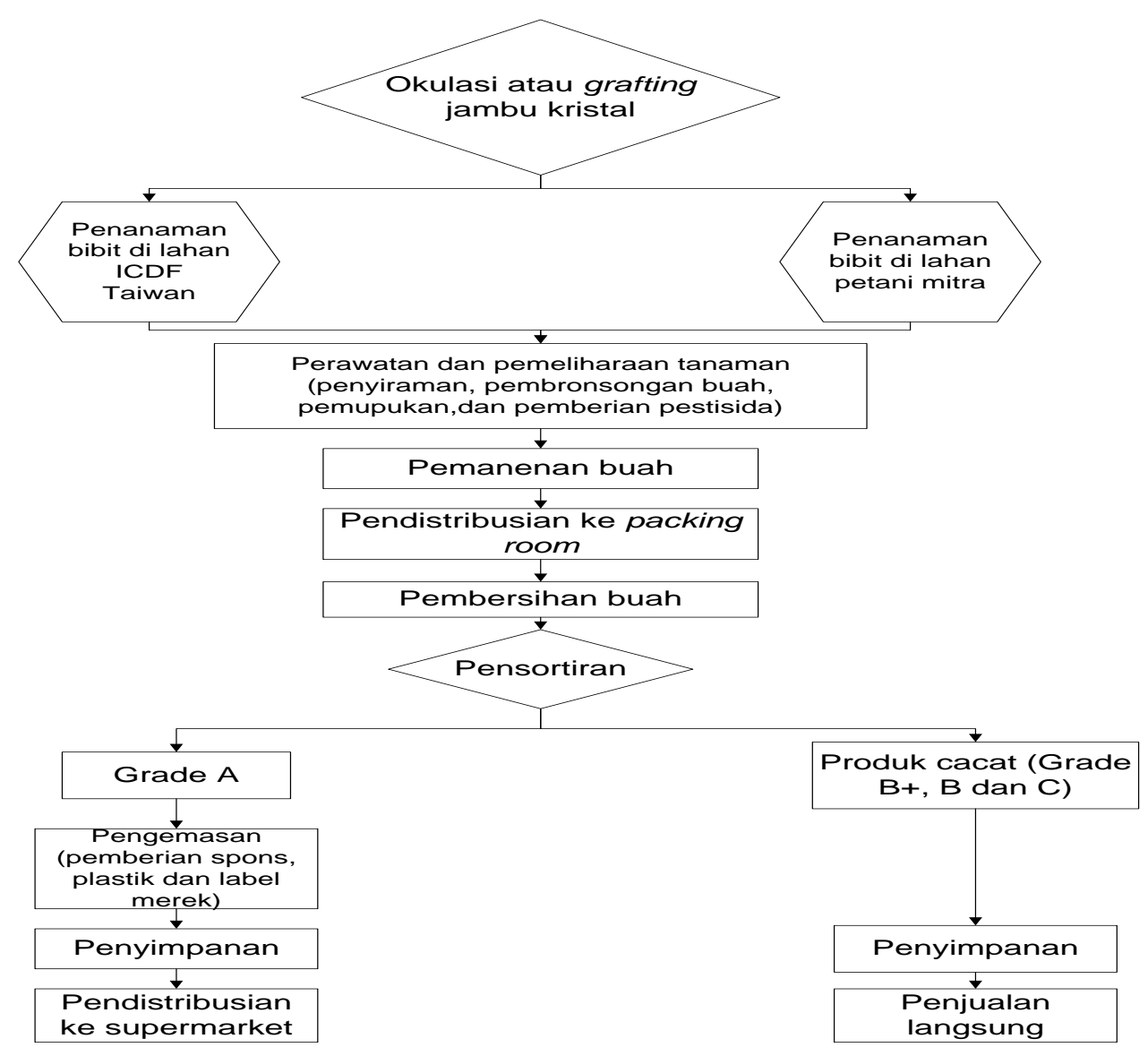

Gambar 3. Process flow diagram jambu Kristal ADC IPB-ICDF Taiwan Bogor

III.3. Pengendalian Mutu Jambu Kristal

Pengendalian mutu jambu Krista terdiri dari tiga tahapan, yaitu :

1. Tahapan Definisi (Define)

Masalah pengendalian mutu yang harus diperhatikan oleh perusahaan untuk mencapai sasaran pemenuhan permintaan pasar adalah jumlah produk cacat jambu Kristal yang tinggi perbandingannya dengan jumlah produksi jambu Kristal grade A, ditambah dengan selisih harga yang cukup besar untuk setiap grade yang dijual oleh ADC IPB-ICDF Taiwan Bogor. Hal ini akan berdampak pada pendapatan dari penjualan yang diterima perusahaan. Jambu Kristal grade A dijual untuk memenuhi permintaan pasar supermarket dan toko buah berskala besar. Perusahaan juga seringkali mengalami kerugian, karena harus membuang produk cacat jambu Kristal (untuk grade $\mathrm{B}+, \mathrm{B}$ dan $\mathrm{C}$ ) yang mengalami chilling injury, yaitu gangguan fisiologis yang disebabkan oleh suhu rendah (bukan suhu pembekuan) sehingga mengalami beberapa gejala kerusakan setelah dikembalikan pada suhu normal (non-chilling), (Jackman et al. 1988 dalam Marangoni et al. 1996).

2. Tahapan Pengukuran (Measure)

Pada tahap measure atau pengukuran dilakukan pengamatan terhadap tipe kecacatan yang paling sering terjadi pada jambu Kristal produksi ADC IPB-ICDF Taiwan Bogor dengan menggunakan diagram Pareto. Diagram Pareto dibuat dengan menggunakan data pengamatan yang dilakukan peneliti, yang telah dicatat pada kertas 
periksa (checksheet). Kertas periksa berisikan data frekuensi masing-masing tipe kecacatan jambu Kristal yang diproduksi selama penelitian berlangsung yaitu enam hari kerja, mulai tanggal 26 Desember 2012 hingga 3 Januari 2013. Pengambilan contoh dilakukan dengan metode purposive sampling, yaitu teknik pengambilan contoh berdasarkan tujuan atau pertimbangan tertentu Rentang waktu ini dipilih karena siklus panen jambu Kristal terjadi setiap 3 atau 4 hari sekali bahkan bisa lebih cepat sehingga dalam rentang waktu enam hari kerja, peneliti telah mendapatkan data jumlah per tipe kecacatan yang dihasilkan selama tiga kali panen jambu Kristal baik dari lahan ADC IPB-ICDF Taiwan Bogor maupun lahan petani. Hasil pengamatan dalam kertas periksa dapat dilihat pada Tabel 4.

Tabel 4. Kertas periksa tipe kecacatan jambu Kristal tanggal 26 Desember 2012 hingga 3 Januari 2013

\begin{tabular}{lccccccc}
\hline \multicolumn{1}{c}{ Tipe Kecacatan } & \multicolumn{7}{c}{ Tanggal } \\
\cline { 2 - 8 } & 26 Des & 27 Des & 28 Des & 31 Des & 2 Jan & 3 Jan & Total (buah) \\
\hline Bintik cokelat & 496 & 35 & 91 & 68 & 545 & 548 & 1783 \\
Bercak kehitaman & 282 & 26 & 45 & 45 & 222 & 145 & 765 \\
Kulit mengelupas & 118 & 5 & 255 & - & 94 & 56 & 528 \\
Masih Hijau & 34 & 12 & 7 & - & 32 & 376 & 461 \\
Bakal busuk & 6 & 1 & 274 & - & 76 & 62 & 419 \\
Lembek/terlalu matang & 42 & - & 12 & 31 & 86 & 91 & 262 \\
Kotoran putih & 2 & - & - & 4 & - & - & 6 \\
Gagal okulasi & - & - & - & - & 2 & - & 2 \\
\hline \multicolumn{1}{c}{ Total } & $\mathbf{9 8 0}$ & $\mathbf{7 9}$ & $\mathbf{6 8 4}$ & $\mathbf{1 4 8}$ & $\mathbf{1 0 5 7}$ & $\mathbf{1 ~ 2 7 8}$ & $\mathbf{4 2 2 6}$ \\
\hline
\end{tabular}

Pada Tabel 4 tersebut, diurutkan tipe kecacatan dari jumlah paling banyak ditemukan dalam inspeksi hingga jumlah paling sedikit. Untuk tipe kecacatan yang memiliki persentase kurang dari $1 \%$ akan dihapuskan. Persentase jumlah cacat dari masing-masing tipe kecacatan berdasarkan hasil pengurutan dapat dilihat pada Gambar 4.

Hasil pengurutan persentase jumlah cacat yang ditemukan dalam inspeksi digunakan untuk mengetahui tipe kecacatan potensial yang paling banyak ditemui pada proses produksi jambu Kristal di ADC IPB-ICDF Taiwan Bogor. Dari Tabel 4 tersebut dapat disimpulkan bahwa tipe kecacatan yang paling banyak ditemukan dalam inspeksi adalah bintik cokelat dan bercak kehitaman. Berdasarkan Tabel 4, dapat dibuat diagram pareto untuk menggambarkan tipe kecacatan jambu dari tertinggi hingga terendah yang dapat dilihat pada Gambar 4.

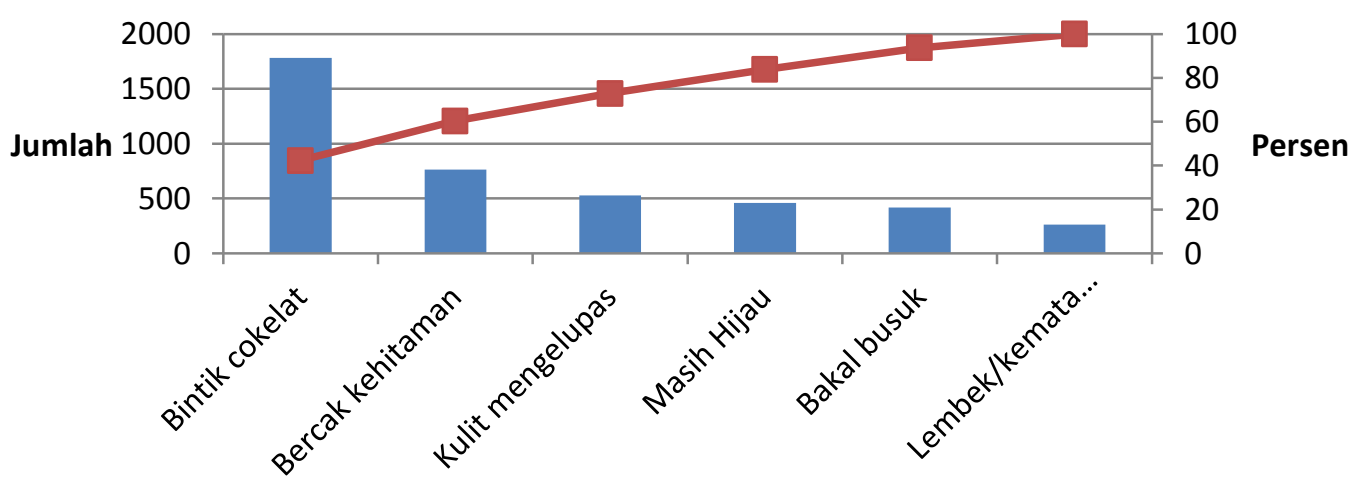

Gambar 4. Diagram Pareto 
Dilihat dari hasil diskusi dengan tim jambu Kristal di ADC IPB-ICDF Taiwan Bogor, dapat ditentukan titik kritis permasalahan penyebab tipe kecacatan dari jambu Kristal atau Critical to Quality (CTQ) antara lain :

a. Pembibitan terdiri dari bibit gagal okulasi dikarenakan kesalahan prosedur okulasi, sehingga tidak menghasilkan bibit jambu Kristal, tetapi jambu lokal; dan faktor keterlambatan melakukan tahapan okulasi menyebabkan bibit tanaman terlanjur tua, sehingga produktivitas menurun

b. Keadaan lingkungan terdiri dari cuaca, curah hujan, penyinaran sinar matahari, suhu udara dan kelembaban udara

c. Pemupukan terdiri dari kesalahan takaran pemberian pupuk, kesalahan tata cara pemupukan dan keterlambatan pemberian pupuk

d. Perawatan terdiri dari keterlambatan pemberian pestisida, kesalahan takaran pemberian pestisida, keterlambatan pembungkusan dengan plastik, keterlambatan pengontrolan dan penanganan buah yang terkena hama dan penyakit

e. Panen terdiri dari keterlambatan dan/atau terlalu cepat pemetikan buah

f. Pasca panen terdiri dar kesalahan metode pencucian buah, sehingga merusak tekstur kulit buah, keteledoran pada saat distribusi, jarak pengiriman yang jauh, moda transportasi yang seadanya dan penyimpanan dalam chiller.

Langkah selanjutnya pada tahapan pengukuran (measure), yaitu dilakukan perhitungan pergeseran sigma. Nilai Defect per million Opportunity (DPMO) menunjukkan kapabilitas produksi selama periode tersebut. Dari hasil perhitungan six sigma didapatkan bahwa proses produksi jambu Kristal ADC IPB-ICDF Taiwan Bogor memiliki kapabilitas produksi masih rendah dilihat dari nilai DPMO masih cukup tinggi, yaitu 124975 artinya dalam 1000000 kesempatan produksi, terdapat kemungkinan 124975 buah jambu Kristal yang cacat. Hasil perhitungan nilai six sigma tersebut mengacu pada konversi nilai DPMO berdasarkan tabel Motorola's 6-Sigma Process (Normal Distribution). Hasil perhitungan DPMO dan nilai sigma selama tahun 2012 dapat dilihat pada Tabel 5.

Tabel 5. Hasil perhitungan nilai DPMO dan nilai six sigma

\begin{tabular}{|c|c|c|c|c|c|c|}
\hline Bulan-Tahun & $\begin{array}{c}\text { Jumlah Panen } \\
\text { (Kg) }\end{array}$ & $\begin{array}{c}\text { Jumlah } \\
\text { Cacat (Kg) }\end{array}$ & Jumlah CTQ & DPO & DPMO & SIX SIGMA \\
\hline Januari 2012 & 6386.5 & 4788.9 & 6 & 0.125 & 124975 & 2.66 \\
\hline Februari 2012 & 7083.4 & 5553.3 & 6 & 0.131 & 130665 & 2.63 \\
\hline Maret 2012 & 3670.4 & 2868.4 & 6 & 0.130 & 130249 & 2.63 \\
\hline April 2012 & 2506.2 & 1719.4 & 6 & 0.114 & 114343 & 2.71 \\
\hline Mei 2012 & 677 & 457.2 & 6 & 0.113 & 112555 & 2.72 \\
\hline Juni 2012 & 1293.9 & 878.7 & 6 & 0.113 & 113185 & 2.71 \\
\hline Juli 2012 & 5718.6 & 3667.3 & 6 & 0.107 & 106881 & 2.75 \\
\hline Agustus 2012 & 3176.3 & 2091.6 & 6 & 0.110 & 109750 & 2.73 \\
\hline September 2012 & 4982.1 & 3072 & 6 & 0.103 & 102768 & 2.77 \\
\hline Oktober 2012 & 1041.9 & 515.9 & 6 & 0.083 & 82526 & 2.89 \\
\hline November 2012 & 586.5 & 363.3 & 6 & 0.103 & 103240 & 2.76 \\
\hline Desember 2012 & 3000.3 & 1841.4 & 6 & 0.102 & 102290 & 2.77 \\
\hline
\end{tabular}

Pengendalian mutu dengan menggunakan metoda six sigma masih sedikit dipakai di Indonesia. Umumnya metode ini dipakai pada industri manufaktur dan perbankan. Berdasarkan perbandingan manfaat tingkat pencapaian sigma pada rataan 
industri di dunia yang terdapat pada Tabel 6, tingkat pencapaian rataan industri di Indonesia masih berada di kisaran 2-Sigma. Pencapaian tingkat sigma ini masih sangat jauh dari target kapabilitas sigma yang mencapai 6-Sigma (3.4 DPMO). Begitu juga dalam penelitian ini, perhitungan sigma yang dilakukan pada perusahaan yang bergerak di agribisnis, yaitu ADC IPB-ICDF Taiwan, Bogor masih rendah yaitu berada di kisaran 2-sigma. Perusahaan yang bergerak di agribisnis memang lebih sulit untuk menerapkan metode six sigma, yaitu pengendalian mutu dengan target pencapaian yang sangat ketat atau tingkat kecacatan mendekati nol (zero defect). Hal ini dikarenakan produk agribisnis yang rentan dan dipengaruhi oleh berbagai faktor alam yang sulit untuk dikendalikan, sehingga saat ini ADC IPB-ICDF Taiwan Bogor belum realistis untuk mengaplikasikan six sigma pada proses produksi jambu Kristal.

Tabel 6. Manfaat pencapaian beberapa tingkat sigma

\begin{tabular}{|c|c|c|}
\hline \multicolumn{3}{|c|}{ Cost of Poor Quality (COPQ) } \\
\hline $\begin{array}{c}\text { Tingkat Pencapaian } \\
\text { Sigma }\end{array}$ & DPMO & $\begin{array}{l}\text { COPQ sebagai persentase dari nilai } \\
\text { penjualan }\end{array}$ \\
\hline 1-Sigma & 691462 (sangat tidak kompetitif) & Tidak dapat dihitung \\
\hline 2-Sigma & 308538 (rataan industri di Indonesia) & Tidak dapat dihitung \\
\hline 3-Sigma & 66807 & $25-40 \%$ dari penjualan \\
\hline 4-Sigma & 6210 (rataan industri USA) & $15-25 \%$ dari penjualan \\
\hline 5-Sigma & 233 (rataan industri Jepang) & 5-15\% dari penjualan \\
\hline 6-Sigma & 3.4 (Industri kelas dunia) & $<1 \%$ dari penjualan \\
\hline
\end{tabular}

\section{Tahapan Analisis (Analyze)}

Pada Gambar 5 menunjukkan penyebab-penyebab dari kecacatan bakal busuk dan bonyok atau remuk antara lain kelalaian pekerja, pendistribusian, penyakit dan hama, lingkungan, serta penyimpanan.

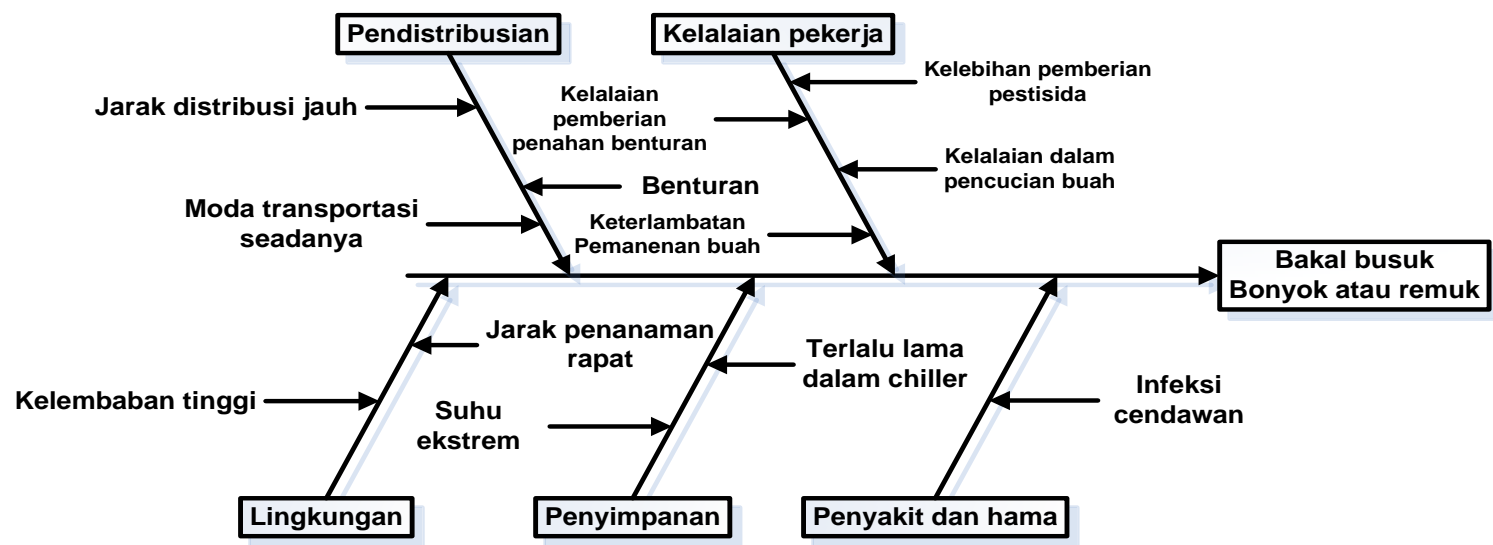

Gambar 5. Diagram sebab akibat bakal busuk dan bonyok atau remuk

Pada Gambar 6, tulang ikan menunjukkan beragam penyebab dari kecacatan bintik atau bercak cokelat kehitaman pada kulit buah jambu Kristal, antara lain penyakit tanaman, hama, lingkungan, metode perawatan dan kelalaian pekerja. 


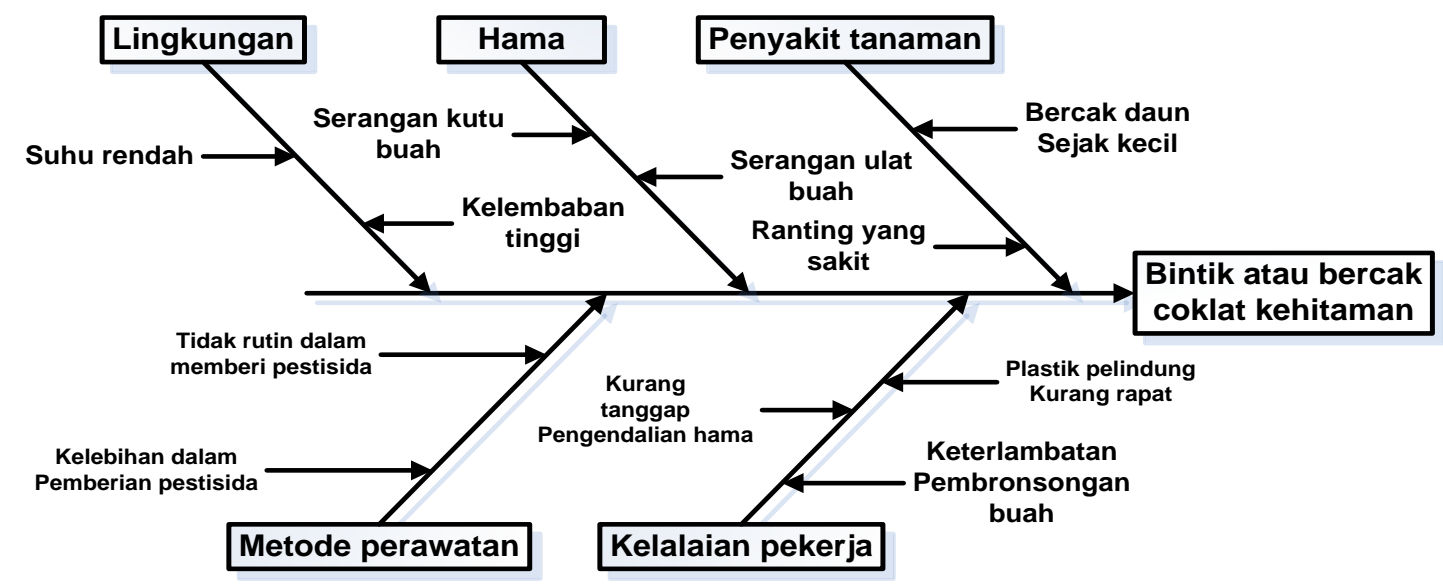

Gambar 6. Diagram sebab akibat bintik atau bercak cokelat kehitaman

Diagram sebab akibat untuk penyebab dari tipe kecacatan terdiri atas kulit buah mengeluas, buah masih hijau, buah terlalu matang, kotoran putih pada kulit buah dan tanaman yang tidak menghasilkan jambu Kristal dapat dilihat pada Gambar 7.

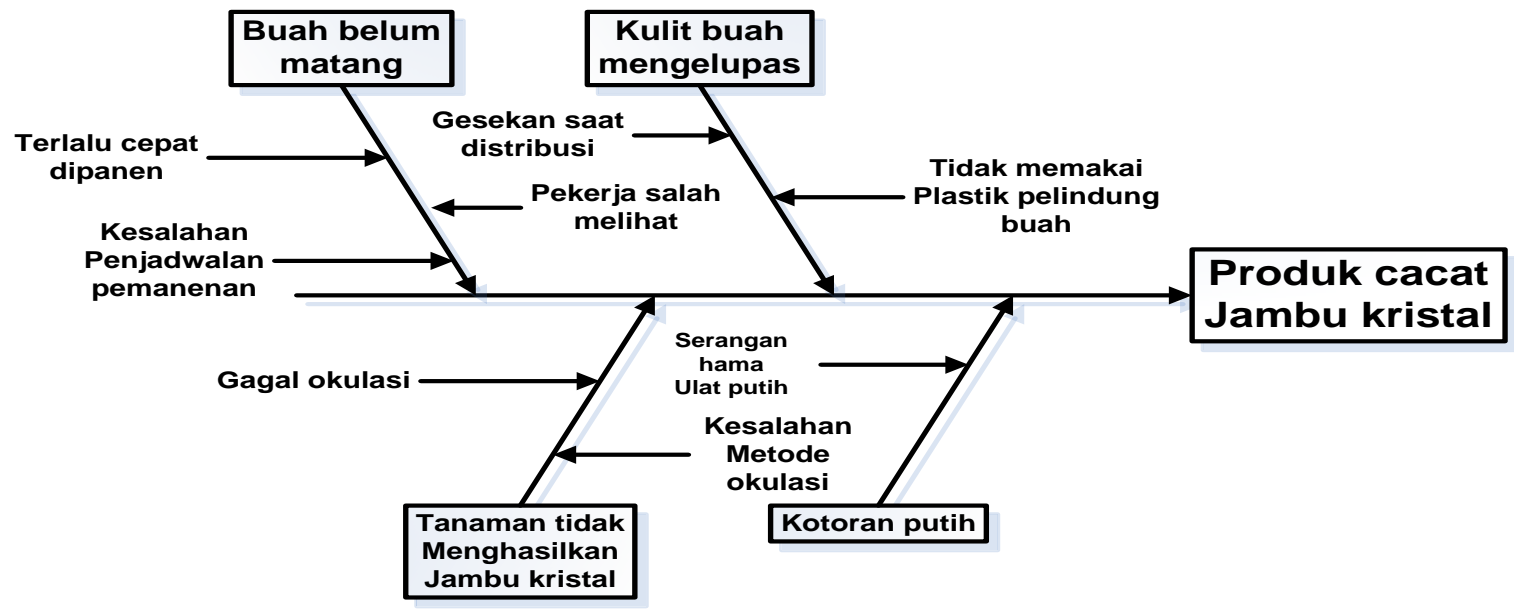

Gambar 7. Diagram sebab akibat produk cacat jambu Kristal

Selain itu, dari hasil wawancara dengan pengelola jambu Kristal dari ADC IPB ICDF Taiwan Bogor dan observasi ke lapangan, didapatkan fakta bahwa kekurangan pasokan jambu Kristal dari perusahaan dikarenakan adanya sistem gabruk hasil panen dari lahan petani mitra. Sistem gabruk adalah penjualan hasil panen jambu Kristal ke pengumpul atau tengkulak tanpa dilakukan pensortiran terlebih dahulu dengan pemberlakuan satu harga untuk setiap grade, yaitu Rp5 000-Rp7 000 per kilogram. Dari hasil wawancara dengan salah satu petani mitra sekaligus pengumpul hasil panen dari 11 orang petani di Desa Bantarsari dan sekitarnya, jumlah hasil panen rataan per bulan yang dikirim ke ADC IPB-ICDF Taiwan Bogor dibandingkan ke pasar lain seperti bazar Kementerian Pertanian, stand di Dinas Pertanian dan Kehutanan Bogor, stand di kantor Walikota Bogor dan beberapa supermarket yang menjadi langganan petani adalah 1:5. Hal ini menyimpulkan bahwa loyalitas petani mitra masih kurang terhadap perusahaan, dikarenakan hasil panennya tidak seluruhnya dikirim ke kantor ADC IPB- 
ICDF Taiwan Bogor. Beberapa alasan petani yang melakukan sistem gabruk, antara lain hasil panen sedikit, lokasi kantor yang jauh dari lahan petani mitra dan biaya transportasi yang tidak sebanding dengan hasil penjualan panen yang diterima saat menjual ke ADC IPB-ICDF Taiwan Bogor, menyebabkan lebih memilih menjual hasil panen dengan sistem gabruk, bahkan ada beberapa petani yang memberlakukan sistem pembelian "jemput", yaitu pembeli datang langsung ke tempat pengumpul, dikarenakan dari hasil kumulatif pendapatan penjualan lebih menguntungkan.

4. Tahapan Perbaikan (Improve)

Tipe kecacatan jambu Kristal dibagi menjadi penyebab yang sulit dikendalikan dan mudah dikendalikan. Tipe kecacatan seperti bakal busuk dan bintik cokelat atau bercak kehitaman adalah beberapa tipe kecacatan yang sulit untuk dikendalikan. Kecacatan ini disebabkan oleh banyak faktor seperti lingkungan, penyakit dan hama serta faktor human error, sehingga risiko terjadinya tipe kecacatan ini memiliki peluang sangat tinggi. Sedangkan, tipe kecacatan kulit buah mengelupas, buah masih hijau dan buah kematangan adalah beberapa tipe kecacatan yang mudah dikendalikan. Kecacatan ini disebabkan oleh faktor kesalahan pekerja seperti keteledoran yang sebenarnya bisa dihindari, sehingga akan berdampak pada penurunan jumlah produk cacat.

Penanggulangan tipe kecacatan jambu Kristal yang sulit dikendalikan dimulai dengan mengetahui penyebab potensial yang menyebabkan kecacatan dari prioritas tertinggi hingga terendah dengan menggunakan Failure Mode and Effect Analysis (FMEA), untuk dijadikan dasar merumuskan rekomendasi action planbagi perusahaan. Penilaian kuesioner untuk metode FMEA, yaitu skor Severity (SEV), Occur (OCC) dan Detect (DET) setiap item penyebab kecacatan jambu Kristal dilakukan oleh tim jambu Kristal ADC IPB-ICDF Taiwan Bogor. Berdasarkan penilaian tersebut dapat dihitung RPN (Risk Priority Number), yaitu hasil perkalian dari SEV, OCC, dan DET. Responden memberikan skor dari 1-10 pada kolom SEV, yaitu tingkat keseriusan atau keparahan yang akan diakibatkan oleh setiap mode kegagalan. OCC adalah tingkat kemungkinan terjadinya kegagalan dan DET adalah tingkat pendeteksian kegagalan diakibatkan kemungkinan lolosnya penyebab kegagalan dari tindakan kontrol yang sudah dilakukan perusahaan.

Hasil diskusi dengan tim jambu Kristal (dari diagram FMEA dapat dilihat pada didapatkan prioritas item atau modus kegagalan potensial dari tertinggi hingga terendah untuk penyebab kecacatan bintik atau bercak pada kulit buah jambu Kristal) adalah:

1. Kelalaian pekerja dalam memberikan pestisida karena kelelahan atau akibat beriteraksi dengan sesama pekerja ( $R P N=200)$

2. Kelalaian pekerja dalam pengendalian hama tanaman, misal kurang tanggap mendeteksi adanya tanaman yang terserang hama atau penyakit ( $R P N=162)$

3. Kondisi lingkungan yang memiliki suhu lembab dan teduh mendukung perkembangbiakan hama sehingga serangan hama meningkat dan menyerang buah (RPN=128)

4. Bibit tanaman yang membawa penyakit bercak pada tanaman ( $R P N=96)$

Tindakan pencegahan, untuk mengendalikan penyebab kegagalan potensial dari kecacatan produk jambu Kristal berupa bintik atau bercak kecokelatan pada kulit buah, 
yaitu dengan melakukan pengontrolan pekerja saat pemberian pestisida yang telah terjadwal. Pengontrolan ini untuk menghindari kelalaian pekerja yang kelebihan dalam memberikan dosis dan segera membuang jambu Kristal yang telah terlihat memiliki bintik atau bercak cokelat kehitaman yang melebar, karena hama atau penyakit agar tidak terkena ke buah jambu Kristal yang lain. Selain itu, dibuat shift bagi pekerja untuk pembagian pekerjaan dalam perawatan dan pemeliharaan tanaman. Hal ini dilakukan agar penanganan seluruh tanaman jambu Kristal lebih terkendali dan terawasi untuk mencegah kelalaian dalam pengendalian hama dikarenakan lahan yang cukup luas.

Sedangkan untuk tipe kecacatan bakal busuk pada jambu Kristal, berdasarkan penilaian terhadap SEV, Occur dan Detect didapatkan kesimpulan bahwa penyebab kegagalan potensial berdasarkan prioritas tertinggi ke terendah adalah:

a. Kelalaian pekerja dalam pemanenan misal karena buah terlambat dipanen, sehingga terlalu matang di pohon ( $R P N=216)$.

b. Kelalaian pekerja dalam pemberian pestisida misal kelebihan pestisida menyebabkan kulit buah berwarna merah (RPN=192).

c. Pendistribusian dari petani dikarenakan moda transportasi yang seadanya dan jarak distribusi yang jauh dari kantor ADC IPB-ICDF Taiwan Bogor (RPN=189).

d. Pengendalian hama dan penyakit pada tanaman yang menyebabkan bakal busuk pada buah misal berupa infeksi cendawan Botryodiplodia thebromaepat (RPN=162).

e. Kondisi lingkungan misal kelembaban yang tinggi dan penanaman tanaman terlalu rapat jaraknya (RPN=112).

Tindakan pencegahan untuk mengendalikan penyebab kegagalan potensial dari kecacatan produk jambu Kristal berupa proses pembusukan pada buah, yaitu dengan cara pembuatan shift pekerja atau penjadwalan pemanenan buah yang teratur agar lebih terkendali dan buah yang telah matang tidak terlambat dipanen. Penanganan serta pengendalian hama dan penyakit harus benar-benar diperhatikan oleh perusahaan yang bergerak di bidang agribisnis. Perawatan harus lebih rutin dilakukan pada musim hujan karena serangan hama lebih banyak terjadi pada musim ini dikarenakan suhu dan kelembaban yang mendukung perkembangan hama tersebut.

Sedangkan, penanggulangan untuk tipe kecacatan yang mudah dikendalikan harus dilakukan lebih intensif dan ketat. Misalnya untuk tipe kecacatan buah masih hijau dan buah kematangan yang disebabkan oleh keteledoran pekerja saat pemanenan, bisa ditanggulangi dengan pengawasan ketat ketika masa panen. Selain itu, kecacatan kulit buah mengelupas disebabkan oleh keteledoran petani mitra pada saat pasca panen yaitu ketika pendistribusian ke kantor ADC IPB-ICDF Taiwan Bogor. $\mathrm{Hal}$ ini bisa ditanggulangi dengan memberikan edukasi kepada petani untuk lebih berhati-hati dan telaten dalam melakukan pembersihan buah agar tidak merusak tekstur dan kemulusan kulit buah serta memberikan penahan benturan yang berlapis seperti koran atau kertas bekas agar buah tidak remuk atau bonyok saat pendistribusian. Dalam jangka panjang, perusahaan perlu memikirkan lebih lanjut untuk melakukan investasi dengan pendirian kantor cabang baru di daerah penghasil jambu Kristal dari petani mitra potensial dalam meningkatkan produksi, sehingga hasil panen petani mitra lebih mudah terdistribusikan dengan peluang reject yang lebih kecil, dengan demikian produksi jambu Kristal akan meningkat. 


\section{Tahapan Pengendalian (Control)}

Pada tahapan control, batasan penelitian ini hanya sampai penentuan standar pengukuran yang didapat dari perhitungan garis sentral (Central Limit) pada peta kendali. Garis sentral (CL) melukiskan nilai baku yang menjadi dasar perhitungan terjadinya penyimpangan hasil-hasil pengamatan untuk tiap contoh. Upper Control Limit (UCL) atau batas kontrol atas adalah garis yang menunjukkan penyimpangan paling tinggi dari nilai baku dan Lower Control Limit (LCL) atau batas kontrol bawah adalah batas penyimpangan yang paling rendah. Nilai tiap contoh berdasarkan statistik dihitung dan kemudian digambarkan dengan titik-titik dan dihubungkan dengan garis untuk dianalisis.

Langkah-langkah yang ditempuh dalam metode ini (Feigeumbaum dalam Nasution 2005) adalah :

a. Menentukan standar mutu proses

b. Menentukan data yang dibutuhkan

c. Menghitung rataan produksi per periode (a) yaitu $3343.6 \mathrm{~kg}$

d. Menghitung rataan kerusakan per periode (c) yaitu $2318.1 \mathrm{Kg}$

e. Hitung kerusakan maksimum dan kerusakan minimum

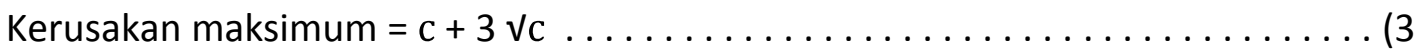

$$
\begin{aligned}
& =2462.6 \mathrm{Kg} \\
& \text { Kerusakan minimum }=\mathrm{c}-3 \mathrm{Vc} \\
& =2173.7 \mathrm{Kg}
\end{aligned}
$$

f. Tentukan $\mathrm{CL}, \mathrm{UCL}$ dan $\mathrm{LCL}$

$$
\begin{aligned}
& \mathrm{CL} \text { : Rata-rata jumlah kerusakan per periode (c) / rataan produksi per periode (a) } \\
& \mathrm{CL}=69 \% \\
& \text { UCL : Kerusakan maksimum / a x 100\% ....................... (5) } \\
& \mathrm{UCL}=74 \% \\
& \mathrm{LCL} \text { : Kerusakan minimum / a x 100\% } \\
& \mathrm{LCL}=65 \%
\end{aligned}
$$

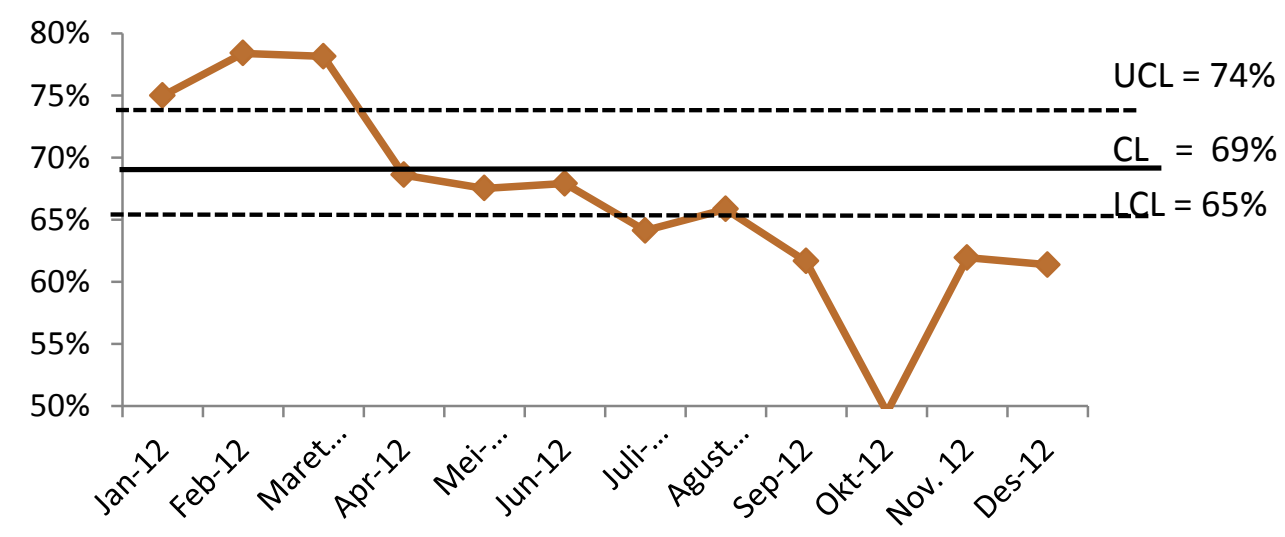

Gambar 8. Peta kendali penyimpangan mutu jambu Kristal tahun 2012

Menurut Hatani (2007), produk cacat atau rusak yang mencapai atau melebihi Batas Kendali Atas (UCL), disimpulkan bahwa proses produksi yang dilakukan perusahaan dianggap tidak efektif. Sedangkan produk cacat atau rusak berada di Batas 
Kendali Bawah ( $(\mathrm{CL})$, maka proses produksi perusahaan dianggap cukup efektif. Pada bulan Juli, September, Oktober, November dan Desember 2012, persentase kecacatan produk jambu Kristal berada di bawah Batas Kendali Bawah (LCL). Hal ini artinya proses produksi yang dilakukan oleh perusahaan pada kelima bulan ini cukup efektif. Penyimpangan mutu yang masih bisa ditolerir terjadi pada proses produksi bulan Mei, Juni dan Agustus 2012, karena persentase kecacatan jambu Kristal masih berada pada daerah yang dibatasi oleh UCL dan LCL. Begitu juga pada bulan April 2012, penyimpangan mutu tepat mencapai garis sentral (69\%), sehingga penyimpangan pada bulan ini dianggap masih bisa ditolerir. Sedangkan pada bulan Januari, Februari dan Maret 2012, persentase kecacatan jambu Kristal melebihi Batas Kendali Atas, artinya proses produksi pada ketiga bulan ini tidak efektif. Berdasarkan pencapaian tingkat sigma tersebut, perusahaan masih belum realistis untuk mengaplikasikan six sigma pada proses produksi jambu Kristal dan hal ini membutuhkan effort pengendalian mutu produk cukup tinggi untuk mewujudkan kondisi zero defect atau tingkat kecacatan mendekati nol. Peta kendali penyimpangan mutu jambu Kristal produksi dari ADC IPB-ICDF Taiwan Bogor selama tahun 2012 dapat dilihat pada Gambar 8.

\section{III.4. Implikasi Manajerial}

Tindakan perbaikan yang dapat dilakukan perusahaan untuk jangka pendek adalah : 1) melakukan tindakan yang tanggap terhadap tanaman atau buah yang telah terkena hama dan penyakit dengan cara sanitasi kebun; 2) menggiatkan intensifikasi lahan seperti pemangkasan, perebahan tanaman dan pemberian fungisida dengan pengawasan yang lebih ketat terutama saat high season (bulan-bulan saat produktivitas jambu Kristal tinggi) misal membuat kartu laporan pengawasan pekerja yang berisi rincian pekerjaan disertai dengan jadwal pekerjaan rutin setiap hari kerja yang harus dilakukan oleh pekerja dan wajib dilaporkan ke tim pengawas; dan 3) pembagian shift pekerja yang lebih teratur dan penjadwalan pekerjaan yang lebih tertata yaitu dengan pembinaan dan pemahaman kembali standard operating procedures (SOP) perawatan dan pemeliharaan.

Tindakan perbaikan untuk jangka menengah meliputi : 1) peningkatan efektivitas dari aktivitas pertemuan rutin dengan kelompok petani, misal membuat stand informasi "asking centre" bagi petani mitra dan pemberian reward bagi petani mitra teladan pada berbagai kategori, misal produktivitas tertinggi, loyalitas dan sebagainya, yang diharapkan dapat mendongkrak hasil panen dan memotivasi petani mitra agar melakukan upaya peningkatan mutu jambu Kristal di lahannya; 2) melakukan penambahan petani mitra menurut spesifikasi perusahaan dan menerapkan perjanjian kontrak; 3) peningkatan kapabilitas karyawan melalui pelatihan dan bimbingan untuk penerapan manajemen yang efektif. Sedangkan tindakan perbaikan untuk jangka panjang meliputi : 1) ekstensifikasi lahan, yaitu perluasan lahan milik ADC IPB-ICDF Taiwan Bogor dan/atau kantor cabang baru di Desa Bantarsari untuk mengurangi produk cacat dari petani mitra yang disebabkan oleh keteledoran saat pendistribusian, sehingga akan berdampak pada peningkatan hasil panen jambu Kristal, dan 2) melakukan tindakan persiapan untuk mendapatkan sertifikasi International Standard Organization (ISO) seperti audit internal mutu jambu Kristal. 


\section{Kesimpulan}

Tahapan pengelolaan produksi jambu Kristal di ADC IPB-ICDF Taiwan Bogor meliputi pemanenan, pembersihan buah, penyortiran, pengemasan, penyimpanan di chiller dan pengiriman. Berdasarkan hasil analisis pengendalian mutu jambu Kristal produksi ADC IPB-ICDF Taiwan Bogor, persentase kecacatan jambu Kristal selama tahun 2012 adalah 69\% dari keseluruhan total jumlah panen. Jenis kecacatan yang biasanya terjadi antara lain bintik atau noda cokelat kehitaman, kulit mengelupas, buah masih hijau atau belum matang, buah lembek atau terlalu matang, dan penyakit bakal busuk pada buah. Dilihat dari seluruh tahapan proses produksi, maka didapatkan enam penyebab produk cacat meliputi pembibitan, keadaan lingkungan, pemupukan, perawatan, panen dan pasca panen. Proses produksi yang tidak efektif terjadi pada bulan Januari, Februari dan Maret 2012 dikarenakan persentase kecacatan jambu Kristal pada bulan-bulan tersebut melebihi Batas Kendali Atas yang ditetapkan (74\%).

Penyebab potensial kecacatan jambu Kristal antara lain penyakit tanaman, serangan hama seperti ulat dan kutu buah, kondisi lingkungan yang memiliki suhu rendah dan kelembaban tinggi, faktor human error, kesalahan operasional seperti keterlambatan pekerja dalam membronsong buah dengan rapat dan juga dalam penanganan jambu Kristal yang telah terkena hama dan penyakit, kesalahan saat pemanenan dan keteledoran dalam pendistribusian.

Berdasarkan perhitungan sigma didapatkan hasil bahwa kapabilitas sigma pada bulan Januari hingga Desember 2012 pada produksi jambu Kristal di ADC IPB-ICDF Taiwan Bogor masih berada di kisaran 2-sigma. Kapabilitas sigma terendah pada bulan Februari dan Maret 2012, (2.63 sigma) dan tertinggi pada bulan Oktober 2012 (2.89 sigma). Hal ini menunjukkan cacat yang dihasilkan masih banyak dan masih berada di bawah target kapabilitas six sigma, sehingga, perusahaan masih belum realistis untuk mengaplikasikan six sigma pada proses produksi jambu Kristal dan membutuhkan effort tinggi untuk mewujudkan kondisi zero defect atau tingkat kecacatan mendekati nol.

\section{Daftar Pustaka}

Dewi SK. 2012. Minimasi defect product dengan konsep six sigma. Jurnal Teknik Industri, 13(1): 43-50

Gaspersz V. 2007. Lean Six Sigma for Manufacturing and Service Industries. Jakarta (ID): PT Gramedia Pustaka Utama.

Hatani La. 2007. Manajemen pengendalian mutu produksi roti melalui statistical quality control (studi kasus pada perusahaan roti Rizky Kendari). Jurnal pada Jurusan Manajemen UNHALU, 1: 1-7.

Marangoni AG, Palma T, Stanley DW. 1996. Membrane effects in postharvest physiology. Postharvest Biology and Technology, 7 (3): 193-217.

Miranda AWT. 2006. Six sigma, Gambaran Umum, Penerapan Proses dan Metode yang digunakan untuk Perbaikan. Yogyakarta (ID): Harvarindo.

Montgomery DC. 2009. Introduction to Statistical Quality Control, Sixth Edition. Arizona (USA): John Wiley \& Sons Inc. 
18|Pratidina, Syamsun, Wijaya - Analisis Pengendalian Mutu Jambu Kristal

Nasution MN. 2005. Manajemen Mutu Terpadu (Total Quality Management). Jakarta (ID): Penerbit Ghalia Indonesia.

Sartin. 2009. Analisa faktor-faktor penyebab defect pada produk bussing dengan metode six sigma di PT MWS Surabaya. Jurnal Tekmapro, 4(1): 1-15.

Ramadhani M, Fariza A, Basuki KD. 2009. Sistem Pendukung Keputusan Identifikasi Penyebab Susut Distribusi Energi Listrik Menggunakan Metode FMEA. Surabaya (ID): Politeknik Elektronika Negeri Surabaya. 